\title{
Footprint lesion: a mirror image of an endometrial polyp
}

\author{
Nitin H. Shah, Aditi V. Joshi*, Sunita Mourya
}

Department of Obstetrics and Gynecology, Vardann Multispeciality Hospital, Kandivali, Mumbai, Maharashtra, India

Received: 11May 2019

Revised: 29 May 2019

Accepted: 11June 2019

\section{*Correspondence:}

Dr. Aditi V Joshi,

E-mail: avj111@gmail.com

Copyright: (C) the author(s), publisher and licensee Medip Academy. This is an open-access article distributed under the terms of the Creative Commons Attribution Non-Commercial License, which permits unrestricted non-commercial use, distribution, and reproduction in any medium, provided the original work is properly cited.

\begin{abstract}
Endometrial polyps may present with a variety of symptomatology. They are mostly benign and commonly encountered in the reproductive age group. Hysteroscopy is an emerging tool for diagnostic as well as a therapeutic purposes. We report a case of endometrial polyp diagnosed on hysteroscopy, with a "footprint", that is contact lesion visible. This is a relatively rare phenomenon, and there is sparse information and literature regarding this entity. Hence the true nature of its effects is yet unknown.
\end{abstract}

Keywords: Endometrial polyp, Footprint lesion, Hysteroscopy

\section{INTRODUCTION}

Endometrial polyps are a common cause for abnormal uterine bleeding. However, many cases are incidentally diagnosed on imaging since patients remain

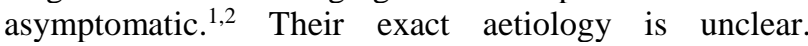
Unopposed or excessive estrogenic stimulation of endometrium is implicated as one of the major factors in pathogenesis. ${ }^{3}$ Hysteroscopy is the gold standard for diagnosing as well as treating polyps. ${ }^{4} \mathrm{~A}$ footprint lesion is like a contact lesion. We describe an interesting observation of this mirror image like lesion noted on hysteroscopy.

\section{CASE REPORT}

A 33 year old, P2L2 presented with complaints of polymenorrhea since 4 months. There were no other associated symptoms. On examination, vital parameters were normal. On cardiovascular and respiratory system examination, no abnormality was detected. On per abdomen examination, abdomen was soft. On per speculum, cervix and vagina were healthy. On per vaginum examination, uterus was normal size, anteverted, bilateral fornices were free. A transvaginal ultrasound showed the presence of an endometrial polyp of 1-2 $\mathrm{cm}$. A diagnostic hysteroscopy with polypectomy was planned after routine investigations. On hysteroscopy, a well circumscribed endometrial polyp was noted to arise from the anterior wall. Interestingly, there was an impression of the polyp on the opposing wall. The posterior uterine wall which was opposite to the polyp revealed a hyperaemic area of the same size as that of the anterior polyp (Figure 1). Due to the similar reflection on the opposite wall, this lesion can be termed as the "mirror image" or "contact lesion" or "foot -print lesion" (Figure 2 and 3). The surrounding area appeared normal. There were no other significant findings.

A hysteroscopic polypectomy was done and specimen was sent for histopathology. She had an uneventful postoperative course and was discharged the same day. Histopathology report revealed a benign endometrial polyp. 


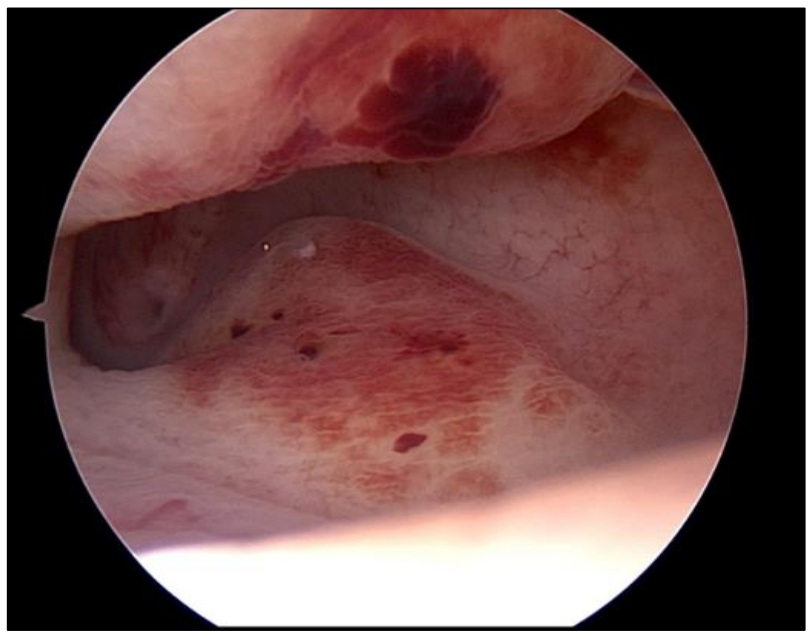

Figure 1: Image depicting a hyperemic area opposite the endometrial polyp, the "foot-print lesion".

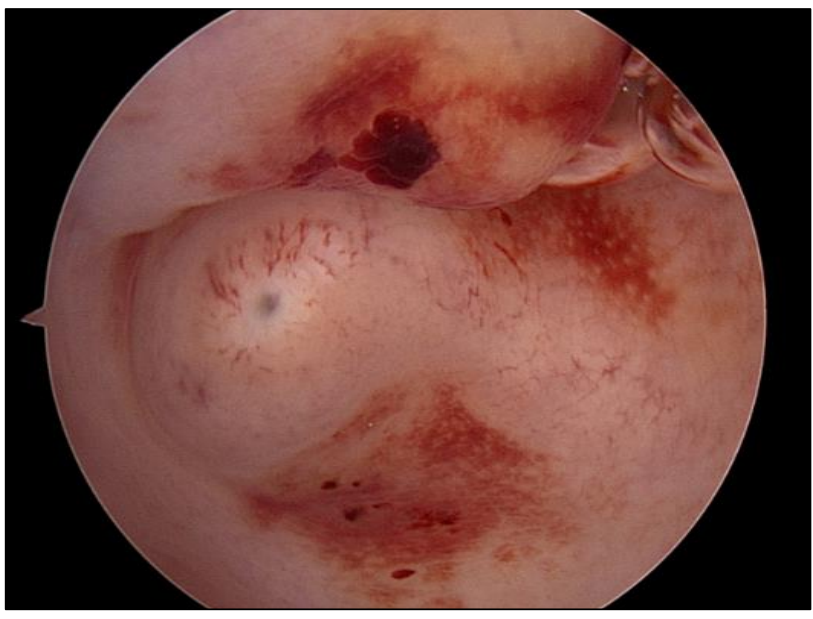

Figure 2: Illustrating the polyp over anterior uterine wall.

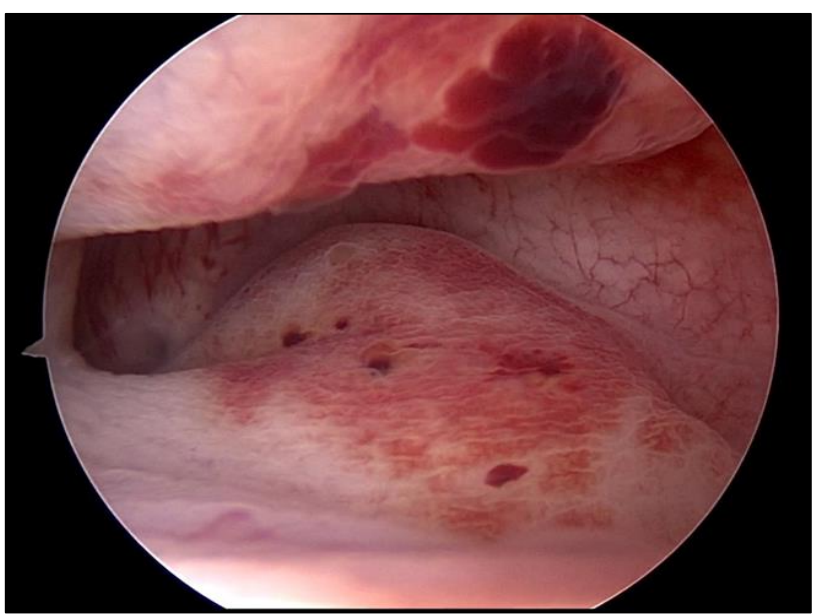

Figure 3: Illustrating apposition of the anterior and posterior uterine walls. The polyp of the anterior wall now seems to have a mirror image onto the posterior wall.

\section{DISCUSSION}

Endometrial polyps are outgrowths of the endometrium. ${ }^{5}$ They are mostly benign; however, some may undergo a malignant transformation. Their incidence varies depending upon the population under study and can range between $7.8-34.9 \% .^{6,7}$ Intrauterine pathologies are diagnosed by transvaginal ultrasound as a first line investigation. However, its sensitivity ranges between $76 \%$ to $96 \%$. $^{7,8}$

The footprint lesion in our case is so named due to the analogy drawn from an actual footprint which arises due to the pressure of the foot over a soft smooth surface. The polyp probably due to the longstanding pressure exerted, left behind a hyperaemic area of contact on the opposing wall. On dynamic changes in the pressure of the distending media on hysteroscopy, the footprint lesion seemed to rise from the posterior wall and had the exact dimensions of its counterpart on the anterior wall (like a reflection seen in a mirror).

There is not much literature on this entity. Authors came across just one case report with similar findings. ${ }^{9}$ Hence, it is difficult to comment regarding the nature of the implications of this finding on hysteroscopy. Most likely, they are benign and occurs as a result of chronic mucosal pressure impact of the primary lesion.

\section{CONCLUSION}

The contact or footprint lesion is a rare hysteroscopic finding. Its clinical implications are yet unknown owing to its rarity and needs further research. However, every hysteroscopic surgeon must be aware of this entity.

Funding: No funding sources

Conflict of interest: None declared

Ethical approval: Not required

\section{REFERENCES}

1. Salim S, Won H, Nesbitt-Hawes E, Campbell N, Abbott J. Diagnosis and management of endometrial polyps:a critical review of literature. J Minim Invasive Gynaecol. 2011;18(5):569-81.

2. Elias RT, Pereira N, Karipcin FS, Rosenwaks Z, Spandorfer SD. Impact of newly diagnosed endometrial polyps during controlled ovarian hyperstimulation on in vitro fertilization outcomes. $\mathrm{J}$ Minim Invasive Gynecol. 2015;22(4):590-4.

3. Lee SC, Kaunitz AM, Sanchez-Ramos L, Rhatigan RM. The oncogenic potential of endometrial polyps: a systematic review and meta-analysis. Obstet Gynecol. 2010;116(5):1197-205.

4. Worldwide AA. AAGL practice report: practice guidelines for the diagnosis and management of endometrial polyps. J Minimally Invasive Gynecol. 2012;19(1):3-10. 
5. Taylor E, Gomel V. The uterus and fertility. Fertil Steril. 2008;89(1):1-6.

6. Lieng $M$, Istre $O$, Sandvik L, Qvigstad E. Prevalence, 1-year regression rate, and clinical significance of asymptomatic endometrial polyps: cross-sectional study. J Minim Invasive Gynaecol. 2009; 16(4):465-71.

7. Feng L, Li D. Evaluation of intrauterine disorders by hysteroscopy and transvaginal sonography. Gynaecol Endoscopy. 2002;11(6):401-4.

8. Gibbs V, Henson J, Hawkins K. A Retrospective Analysis of the Role of Transvaginal Sonography in the Evaluation of Patients with Abnormal
Postmenopausal Bleeding. Ultrasound. 2004;12(4):218-21.

9. Kumar A, Kumar A. Mirror Lesion at Hysteroscopy. J Minim Invasive Gynecol. 2008;15(6):662.

Cite this article as: Shah NH, Joshi AV, Mourya S. Footprint lesion: a mirror image of an endometrial polyp. Int J Reprod Contracept Obstet Gynecol 2019;8:2895-7. 